\title{
Effects of machining abuse on the surface properties of AISI 316L stainless steel
}

DOI:

10.1016/j.jpvp.2017.02.004

\section{Document Version}

Accepted author manuscript

Link to publication record in Manchester Research Explorer

\section{Citation for published version (APA):}

Maurotto, A., Tsivoulas, D., Gu, Y., \& Burke, M. G. (2017). Effects of machining abuse on the surface properties of AISI 316L stainless steel. International Journal of Pressure Vessels and Piping, 151, 35-44.

https://doi.org/10.1016/j.ijpvp.2017.02.004

\section{Published in:}

International Journal of Pressure Vessels and Piping

\section{Citing this paper}

Please note that where the full-text provided on Manchester Research Explorer is the Author Accepted Manuscript or Proof version this may differ from the final Published version. If citing, it is advised that you check and use the publisher's definitive version.

\section{General rights}

Copyright and moral rights for the publications made accessible in the Research Explorer are retained by the authors and/or other copyright owners and it is a condition of accessing publications that users recognise and abide by the legal requirements associated with these rights.

\section{Takedown policy}

If you believe that this document breaches copyright please refer to the University of Manchester's Takedown Procedures [http://man.ac.uk/04Y6Bo] or contact uml.scholarlycommunications@manchester.ac.uk providing relevant details, so we can investigate your claim.

\section{OPEN ACCESS}




\title{
Effects of machining abuse on the surface properties of AISI 316L stainless steel
}

\author{
A. Maurotto ${ }^{\mathrm{a}, *}$, D. Tsivoulas ${ }^{\mathrm{b}, \mathrm{c}}$, Y. Gu${ }^{\mathrm{b}}$, M. G. Burke ${ }^{\mathrm{b}}$ \\ ${ }^{a}$ Nuclear AMRC, The University of Sheffield, Advanced Manufacturing Park, Rotherham, S60 5WG, UK \\ ${ }^{\mathrm{b}}$ Materials Performance Centre, The University of Manchester, Manchester, Oxford Road, M13 9PL, UK \\ ${ }^{\mathrm{c}}$ Clean Energy/Nuclear Services, Amec Foster Wheeler, 601 Faraday Street, Birchwood Park, Warrington, \\ WA3 6GN, UK \\ * Corresponding author's email: a.maurotto@sheffield.ac.uk ; phone +441142158013
}

\begin{abstract}
A Design of Experiments (DoE) approach was used to characterise the effects of dry machining at abusive conditions on the austenitic stainless steel AISI 316L. Surface roughness, hardness, martensite fraction, residual stresses and surface defects (welded chips, cracks) were evaluated against the cutting parameters (speed, depth-of-cut and feed) to build a model weighting their contribution. Results are presented in colour contour plots which allow for an in-depth understanding of the parameters' combined effects on the surface properties of the material upon dry milling. Using the statistical model it was possible to identify optimum combinations of cutting parameters on the grounds of minimising undesirable effects on the material. Eventually, a sample "risk of failure" map was derived by evaluating the impact of the process parameters' statistical variations.
\end{abstract}

Keywords: Austenitic stainless steel; Milling; Martensite; Residual Stress; Surface integrity.

\section{Introduction}

Austenitic stainless steels are used in various industrial applications when high corrosion resistance and ductility are required. They see widespread use in the nuclear and chemical industries; generally in aggressive environments where a passive oxide layer on the surface can prove beneficial [1]. On the other hand, alloyed stainless steels are characterised by poor machinability due to their high ductility and low heat conductivity [2]. One of the main issues arising from abusive machining of stainless steels is the formation of $\alpha^{\prime}$ and $\varepsilon$ martensite, which is believed to be more severe in AISI 304L than in AISI 316L. In any case, careful manufacture is of key importance in maintaining the desirable fatigue and corrosion resistance properties of the finished components 
A well-known consequence of abusive machining is the generation of high residual stresses due to severe deformation on the surface, which results in a strain misfit through the material volume [4]. During the cutting process the material is subject to compressive stresses at the tip of the cutting tool and tensile stresses at its end [5]. Additionally, the heat generated during machining can contribute to increasing the overall tensile stress field [6]. Excessive plastic deformation in stainless steels is also known to promote the formation of strain-induced martensite, ultimately reducing the ductility of the finished surfaces and adding to the development of residual stresses due to the volume misfit between the transformed phase and austenite [7].

The aim of the present work is to characterise the response of AISI 316L to abusive dry-milling conditions using an extended range of cutting parameters and a Design of Experiments (DoE) approach. To this end, a statistical model capable of predicting surface integrity with respect to interactions of the different cutting parameters in challenging machining conditions is employed.

\section{Material and methods}

The material investigated in the current study is a commercially available AISI $316 \mathrm{~L}$ austenitic stainless steel. A rolled, laser-cut, $20 \mathrm{~mm}$ thick plate was band sawn into coupons and the machining tests were carried out on the plane defined by the rolling direction (RD) and normal direction (ND). Care was taken to remove the laser-cut edge prior to any machining process [8]. The machining of a narrow groove J-weld was the selected cutting method due to the combination of side-milling and face-milling which are necessary to create the curvature leading to the fillet on the edge of the sample. Each test was conducted with a new cutting tool edge, as tool wear is known to affect both the magnitude of residual stresses and the surface integrity of the finished components [6].

Experiments were performed on a Mazak Vertical Centre Smart 430A (3-axis milling machine) with a Sandvik Coromill R300 tool head, having a diameter of $53 \mathrm{~mm}$, extra close pitch and 5 insert posts. Commercially available tungsten carbide inserts (grade 1040) with a diameter of $12 \mathrm{~mm}$ (R300-1240) were selected for the machining tests due to their sharp ground edge and hard coating. A $7^{\circ}$ positive rake angle was selected for the tool with the aim of reducing build-up edge formation under the challenging dry milling conditions.

A "Design of Experiments" (DoE) approach was used to minimise the number of trials needed to complete the characterisation. A full factorial design with three centre points $(\mathrm{N}=11)$ was used to 
identify which cutting parameters and their interactions had a statistically significant effect on the measured responses. Tests were always randomised to minimise the effect of slight differences in the cutting conditions or machine/operator effects.

The DoE incorporated three key process parameters (Table 1); depth of cut $\left(a_{p}\right)$, feed per tooth $\left(f_{z}\right)$ and cutting speed $\left(\mathrm{V}_{\mathrm{c}}\right)$. Variability and repeatability of the system's response were estimated by centre point replicates. Analysis was performed using Umetric's software Modde version 10.1.1 and the Partial Least Squares method to process multiple responses at the same time, taking their covariance into account [9].

Table 1: Range of process parameters used in this work.

\begin{tabular}{lll}
\hline Abbreviation & Parameter & Range \\
\hline $\mathrm{V}_{\mathrm{c}}$ & Cutting speed & $120-350 \mathrm{~m} / \mathrm{min}$ \\
$\mathrm{a}_{\mathrm{p}}$ & Depth of cut & $1.5-3.0 \mathrm{~mm}$ \\
$\mathrm{f}_{\mathrm{z}}$ & Feed per tooth & $0.15-0.35 \mathrm{~mm}$ \\
\hline
\end{tabular}

Several responses (Table 2) were recorded from experimental tests in both side-milling and facemilling; residual stresses, roughness, quality, ferrite content, Vickers micro-hardness of the surface at shallow $(\sim 5 \mu \mathrm{m})$ and deep $(>25 \mu \mathrm{m})$ penetration of the indenter. Residual stress measurements were performed using X-ray diffraction in a Proto iXRD Combo residual stress analyser. Electron backscatter diffraction (EBSD) analysis was performed on the machined cross-section samples using an FEI Quanta 650 FEG-SEM operated at $20 \mathrm{kV}$ to assess the thickness of the deformed layer.

Penetrating dye and developer were used to reveal the presence of hidden cracks or welded chips on the surface of the finished component. A certified evaluator performed a standard procedure (RCCM-2007 Class 1) employing Johnson and Allen chemicals; JAP (solvent washable dye), JAC2 (hydrocarbon based solvent), JAD (solvent based developer). Coupons were assigned score numbers according to the number of defects present; 1 for no defects, 2 for one or two defects, and 3 for more than two defects. Strain-induced martensite was assessed using a feritscope (Fischer FMP30) combining eddy currents and magnetic detection by averaging five areas for each sample. Surface roughness was evaluated by a Mitutoyo Surftest SJ-410 stylus instrument, by averaging 10 areas for each sample. Five machined surfaces in the fillet area (face-milled) and five surfaces in the side-milled area were selected for each machining coupon. 
Table 2: Process responses used as model input (aim to minimise them all).

\begin{tabular}{ll}
\hline Response & Type \\
\hline $\mathrm{R}_{\mathrm{a}}$ face-mill & Quantitative continuous \\
$\mathrm{R}_{\mathrm{a}}$ side-mill & “ \\
Residual stress & \\
Ferrite side-mill & “ \\
Vickers hardness (shallow) \\
Vickers hardness (deep) \\
Quality
\end{tabular}

\section{Results}

\subsection{Surface roughness}

Several measurements were averaged for each individual sample to minimise the effects of material inhomogeneity or any accidental handling damage. The standard deviation was used to evaluate the quality of the measured data; replicate samples were used to verify the response of the system.

In Figures 1a and 2a, each point represents the median roughness of a work-piece. Surface roughness $\mathrm{Ra}$ appeared to show little dependence on the cutting parameters with the exception of few extremes. As expected, the results for face-milled and side-milled specimens exhibited completely different spreads, with those for the latter being significantly higher. In both cases the proposed model showed high adherence (R2) and predictive power (Q2) to the experimental results with excellent model validity (MoV) and good reproducibility (Rep). Results were normally distributed in both cases (Figures $1 \mathrm{~b}$ and $2 \mathrm{~b}, 1 \mathrm{~d}$ and $2 \mathrm{~d}$ ) whereas plots $1 \mathrm{c}$ and $2 \mathrm{c}$ identified the coefficients on each model and their statistical significance. 




a)
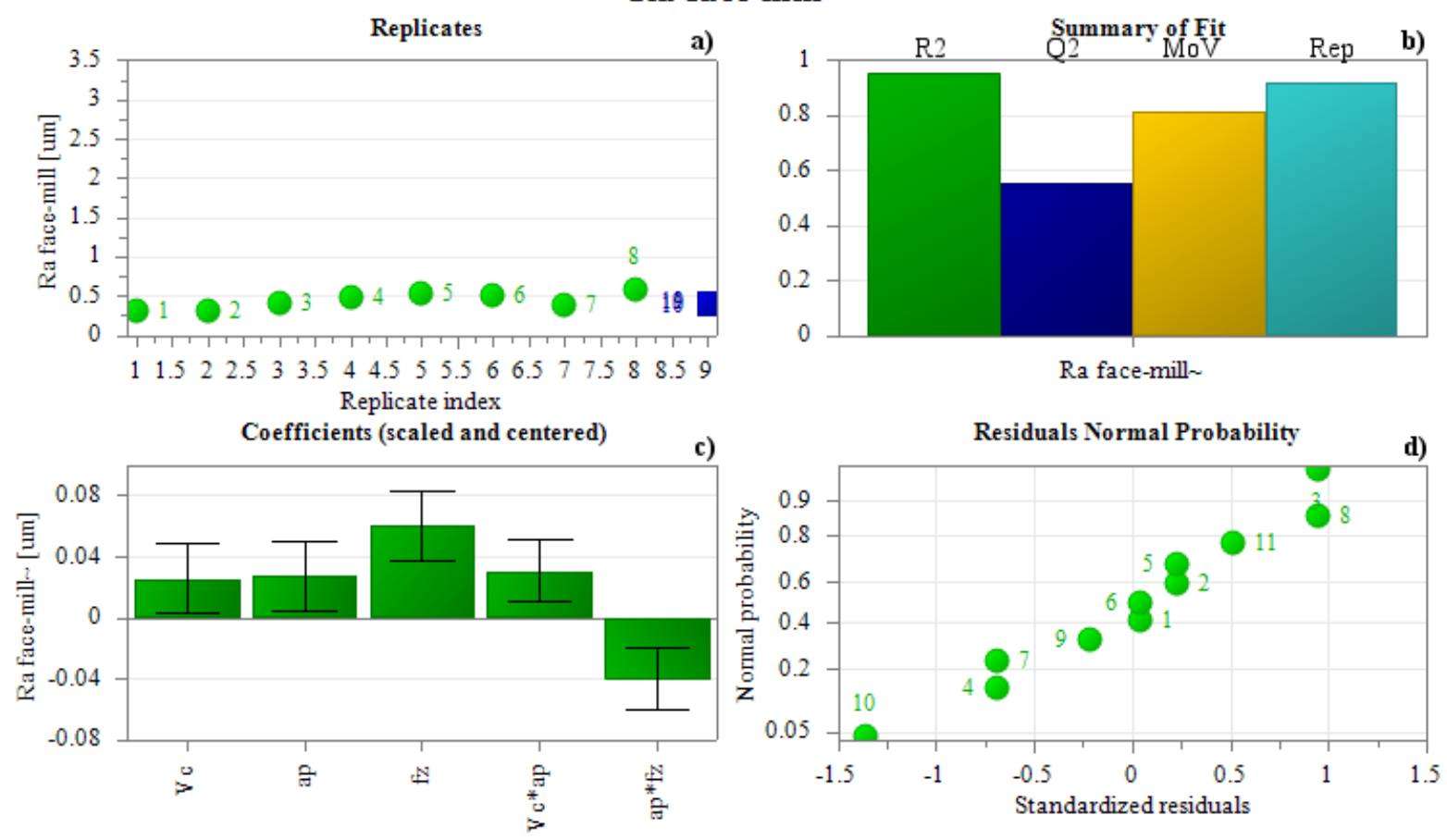

Figure 1: Face-milled surface statistics plot for roughness Ra ; a) result plot, b) model evaluation parameters, c) coefficient effect, d) normality check.


Figure 2: Side-milled surface statistics plot for roughness Ra; a) result plot, b) model evaluation parameters, c) coefficient effect, d) normality check. 


\subsection{Residual stresses}

X-ray diffraction was employed to measure surface residual stresses (Figure 3a). Similar to the previous cases, data obtained from seven areas on the side-milled surface of each work-piece were averaged. This was done to minimise the effects of local heterogeneities in the microstructure and limit influences of potential surface defects, which could affect the stress values. The measured response (RS) exhibited large sensitivity to changes in cutting parameters and a consistent trend for all data points (Figure 3a, 3d). The centre points appeared to exhibit satisfactory reproducibility of the process since the extremes differed by only $\sim 40-50 \mathrm{MPa}$. This value lies within the experimental error of the employed method. Results appeared moderately sensitive to cutting speed variations, and much less sensitive to changes in the depth of cut (Figure 3c). All data points are within \pm 1.6 standard deviation with normally distributed residuals. Satisfactory R2, Q2 and MoV values showed a good fit with the experimental data (Figure 3b).

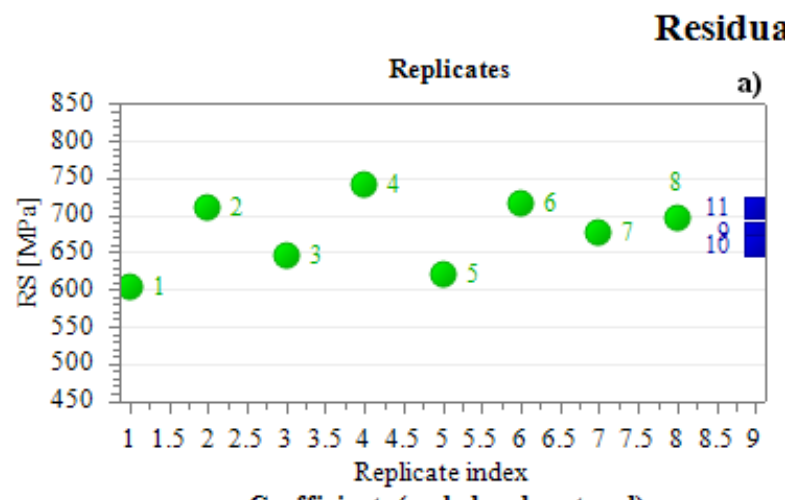

a)
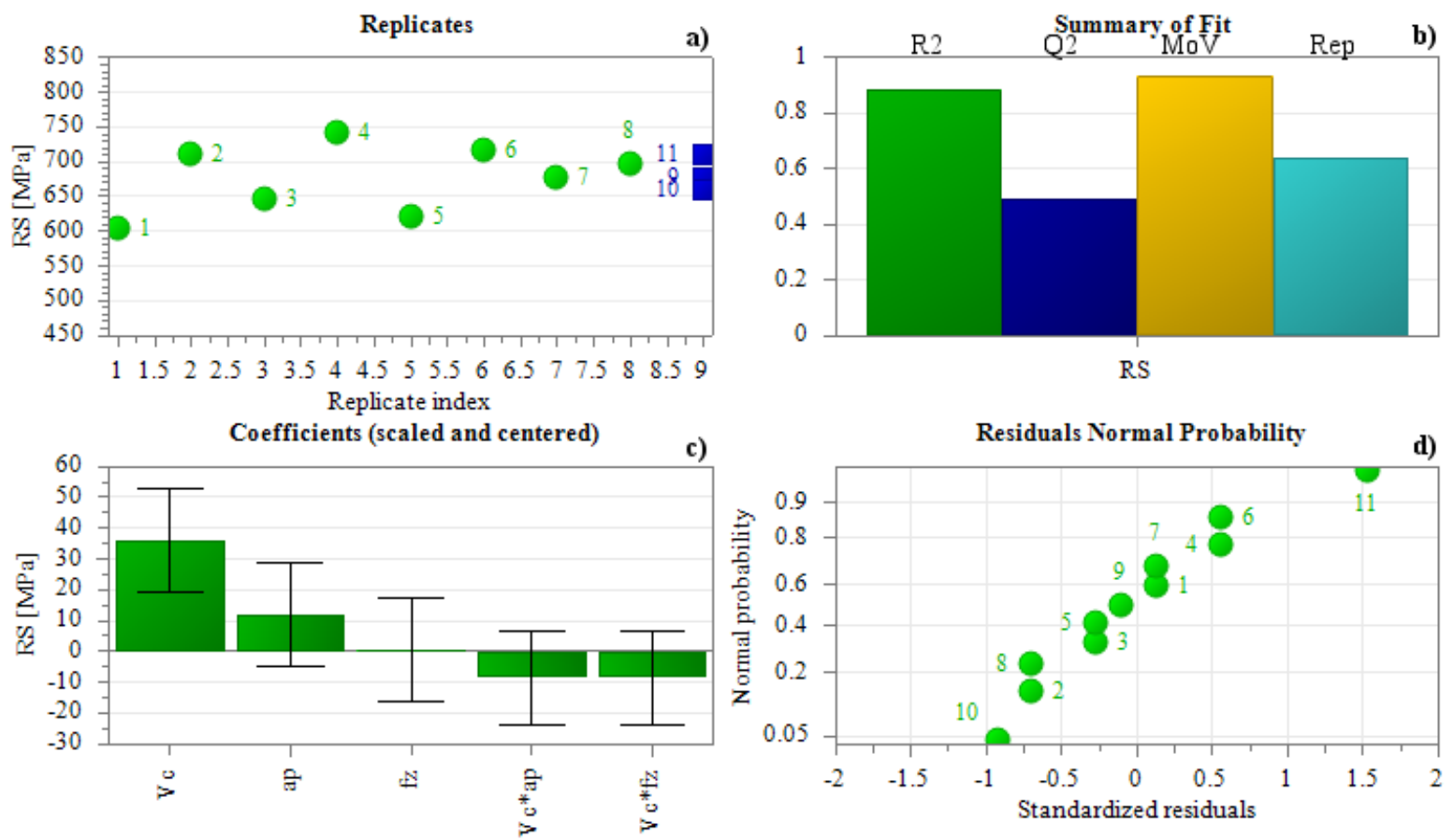

Figure 3: Statistics plot for residual stress (RS) in side-milled surfaces; a) result plot, b) model evaluation parameters, c) coefficient effect, d) normality check.

\subsection{Quality response}

In general the corrosion resistance of a finished component is negatively influenced by the presence of surface defects, such as hidden cracks or pressure-welded chips on the surface, as they could act 
as nuclei or crevices for corrosion. To empirically investigate the presence of surface defects the "colour contrast solvent-removable method" was employed to reveal defects that were not visually detectable..

Figure 4 presents details of the quality response. Most samples scored between 2 and 3 with mainly chip-welding defects observed (Figure 4a). Points appear to be normally distributed with all residuals lying on almost a straight line between \pm 2 standard deviation, an indication of the good quality of the data (Figure 4d).. However, the replicate plot showed high variance in all samples (Figure 4a). The corresponding model was affected by limited adherence to the experimental data and poor predictive power (Figure $4 b$ ).

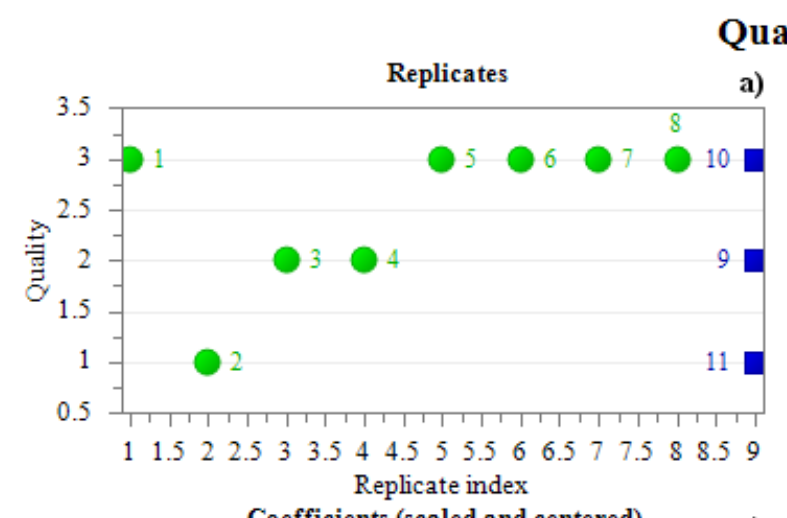

\section{Quality}
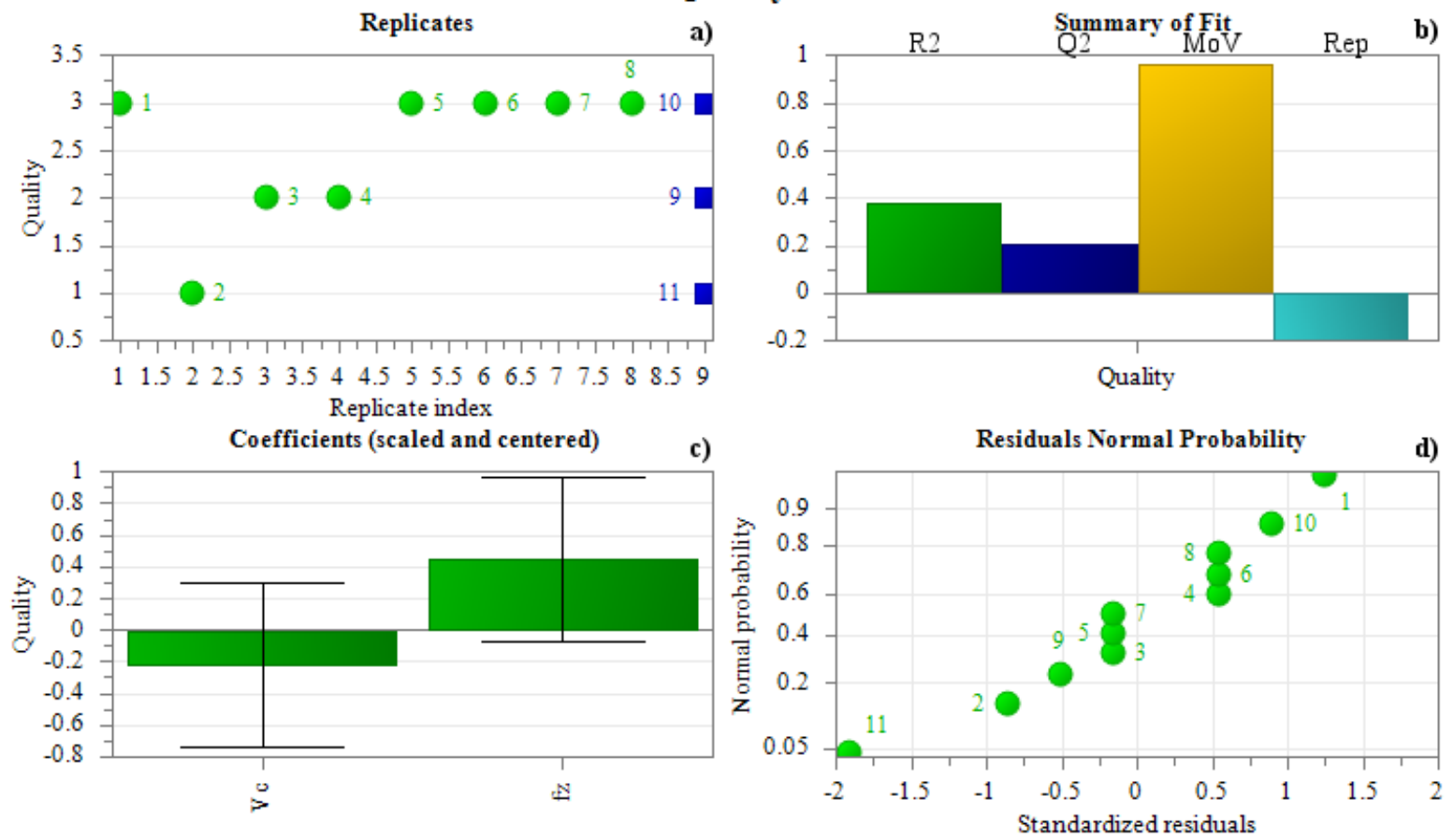

Figure 4: Statistics for Quality response; a) result plot, b) model evaluation parameters, c) coefficient effect, d) normality check.

\subsection{Phase transformations}

Grain size reduction, hardening, and formation of strain-induced $\alpha^{\prime}$ martensite are common features of abusively machined stainless steels. During milling, a fraction of the austenite phase transforms to $\alpha^{\prime}$ martensite and $\varepsilon$ martensite, the remaining austenite deforms by slip or twinning [7]. The surface mechanical properties change greatly adjacent to the surface due to the combined effect of the fine grain size and the presence of a complex deformed layer.

A feritscope produced by Fischer (model FMP30) was used to assess the combined martensite and 
ferrite volume fractions for a measurement depth of approximately $2 \mathrm{~mm}$. In the non-machined material, measurements correspond solely to the amount of delta ferrite in the AISI 316L stainless steel, since no martensite is present. In contrast, after deformation the ferritscope measurement consists of both the delta ferrite and martensite, since they are both ferromagnetic.

Figure 5 shows the predictions of the proposed statistical model for the martensite content. The model appears to have good adherence to the experimental data, as the high R2 value suggests, but poor predictive power (low Q2). Noise in the experimental data prevented the development of a more accurate response model.
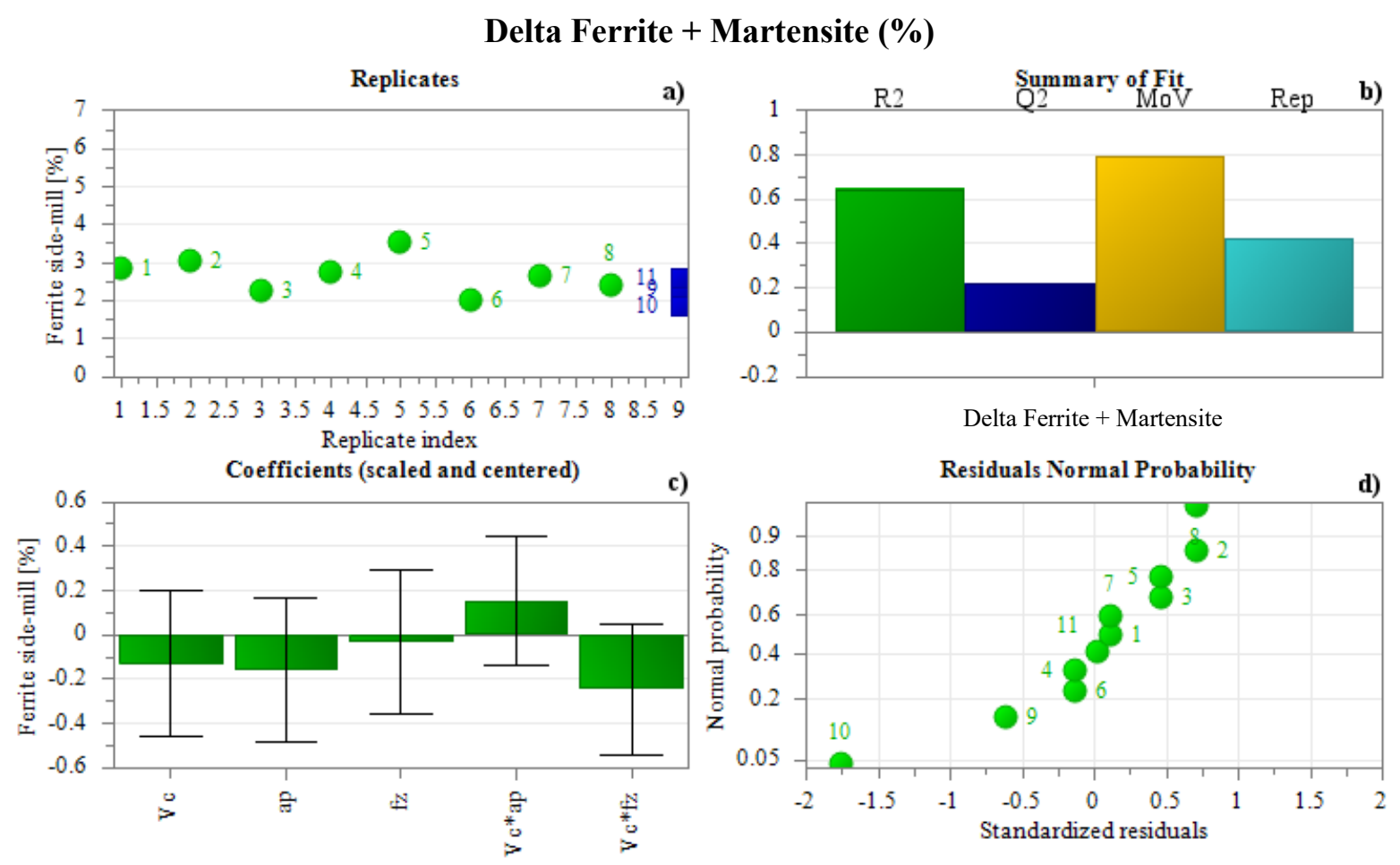

Figure 5: Statistics for delta ferrite + martensite content in side-milled specimens; a) result plot, b) model evaluation parameters, c) coefficient effect, d) normality check.

\subsection{Deformation depth}

Effects of machining on the surface microstructure were investigated in detail by SEM-EBSD analysis. The EBSD maps in Figure 6 illustrate the deformed microstructure immediately below the machined surface in two samples: one with the lowest measured surface hardness, and one with the highest surface hardness.

The regions adjacent to the surface in the Euler colour maps of Figure 6a and d have considerable proportions of non-indexed points due to the extensive local deformation. There is a high density 
of boundaries/deformation bands, indicative of high deformation in the near-surface region. The extent of deformation was progressively reduced with increasing distance away from the surface. Thus, no LAGBs, deformation bands or evidence of strain were present beyond a certain depth in each sample. The depth of the deformed layers in each case was approximately 15 to $20 \mu \mathrm{m}$ with the most severe deformation within $\sim 10$ microns, which is rather low compared to other machining methods such as grinding. Additional information is given by the phase maps in (c) and (f) which illustrate the distribution of ferrite (shown in red colour) within the austenite matrix. This fraction corresponds to the values measured with the feritscope in the non-deformed sample.

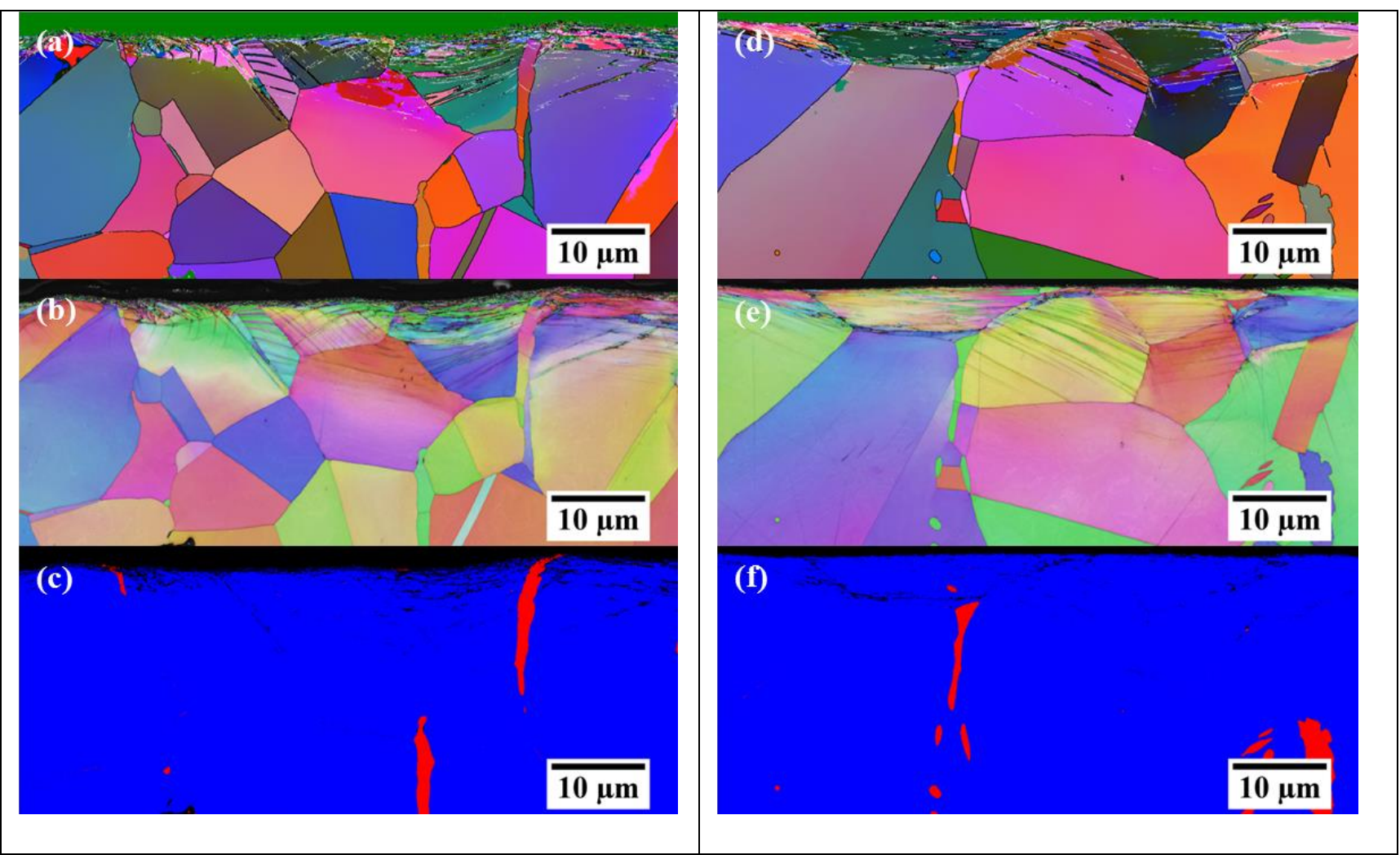

Figure 6: EBSD maps on the machined cross-sections of two specimens showing the depth of the deformed layer: (a) Euler angle colour map $\left(1.5^{\circ}<\mathrm{LAGB}<15^{\circ}\right.$ in thin white lines and HAGBs $>15^{\circ}$ in thick black lines) of the sample with the lowest surface hardness $\left(V_{c}=350 \mathrm{~m} / \mathrm{min}, a_{p}=3 \mathrm{~mm}\right.$, $\mathrm{f}_{\mathrm{z}}=0.15 \mathrm{~mm}$ ), and the corresponding (b) inverse pole figure map and (c) phase map (austenite in blue; delta-ferrite in red); (d) Euler angle colour map of the sample with the highest surface hardness $\left(V_{c}=120 \mathrm{~m} / \mathrm{min}, a_{p}=1.5 \mathrm{~mm}, \mathrm{f}_{\mathrm{z}}=0.35 \mathrm{~mm}\right)$, and the corresponding (e) inverse pole figure map and (f) phase map (austenite in blue; delta-ferrite in red). 


\section{Discussion}

\subsection{Overall evaluation of responses}

The developed statistical model appears to satisfactorily predict effects of abusive machining in AISI 316L and shows a good fit with experimental data (R2) for residual stress (RS), surface roughness ( $\mathrm{Ra}$ in both face- and side-mill) and martensite content (see Figure 9) in side-milled specimens (Figure 7). Predictive power (Q2) was sufficient for the same responses apart from the martensite content. The quality response was not as accurate, since it showed poor R2 and Q2.

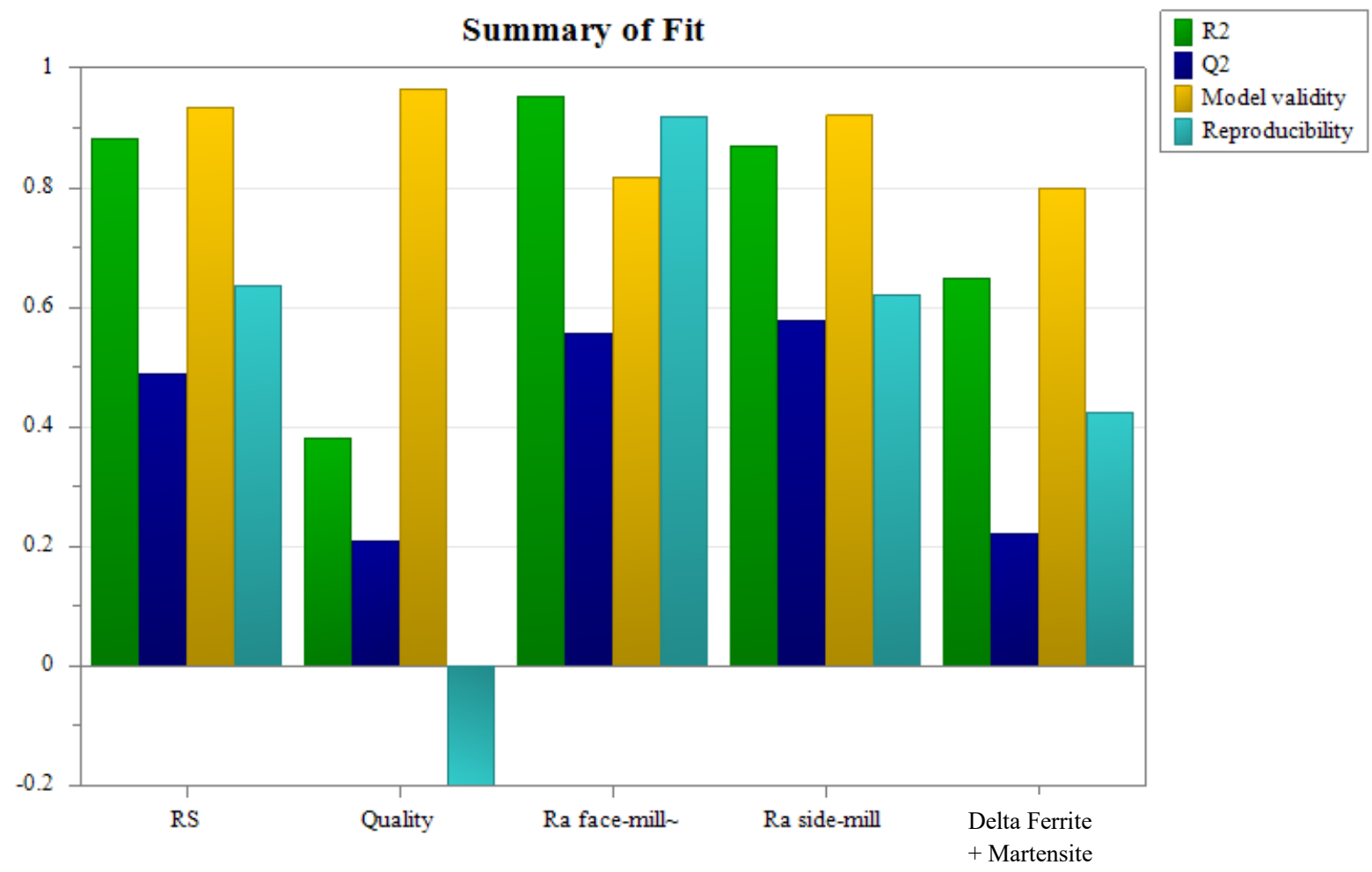

Figure 7: Summary of model validity data for the proposed statistical model.

In order to summarise large amounts of information, contour plots were generated using the developed statistical model. The presence of three parameters would require a 3D space to generate a planar plot; however, this type of plot is difficult to read and interpret. By fixing the response surface at various feed per tooth $\left(f_{z}\right)$ values, $2 \mathrm{D}$ plots were obtained where only cutting speed $\left(\mathrm{V}_{\mathrm{c}}\right)$ and depth of cut $\left(a_{p}\right)$ varied (Figures 8 and 9 ). This approach greatly simplified the analysis of the results.

Although coefficient plots are presented for all the investigated parameters, those for the quality response were not included in this work due to the relative poor quality of the predictions. Quality, however, appeared to be little influenced by the cutting speed and depth of cut, but showed a strong dependence on feed per tooth. Higher $f_{z}$ consistently resulted in a larger number of defects on the 
surface.

\subsubsection{Surface quality}

In this study, surface roughness resulting from hard milling was observed to be well below the common limit of $3.2 \mu \mathrm{m}$ used in the nuclear industry even at the most unfavourable combination of cutting parameters. Face-milled surfaces, in particular, exhibited very low roughness values across the full range of parameters (Figure 8). Instead, side-milled surfaces showed higher roughness values and appeared sensitive to $f_{z}$ variations. This is explained by the presence of periodic cutting marks on the surface, the spacing of which was consistent with $f_{z}$. At high $f_{z}$ the generated cusps were higher and increased the surface roughness value ultimately reducing the quality of the machined component's surface.

Higher feed-per-tooth and cutting speed values also resulted in an increased number of macroscopic defects observed on the surface. This could be explained by sub-optimal chip removal, with chips improperly removed from the cutting area and subsequently pressure-welded onto the surface by the cutting tool [12]. This could be a sign that at those cutting parameters there was an increased formation of edge build-up or a less-than-optimal flow of the chip on the surface of the rake face of the tool [13].

Figure 8: Contour plot of Roughness Ra for face- and side- milled surfaces at; a) $\mathrm{f}_{\mathrm{z}}=0.15 \mathrm{~mm}$, and $\mathrm{b}$ ) $\mathrm{f}_{\mathrm{z}}=0.35 \mathrm{~mm}$.

The roughness of face-milled specimens appeared to increase marginally with $a_{p}$ and $f_{z}$ but remained below $3.2 \mu \mathrm{m}$ in the full experimental range (Figure 8a,b). Even at cutting speeds that were almost three times the recommended values $\left(V_{c}=135 \mathrm{~m} / \mathrm{min}, a_{p}=0.15 \mathrm{~mm}, \mathrm{f}_{z}=0.1 \mathrm{~mm}\right)$ with high $a_{p}$ and $f_{z}$, surface roughness was always below the study set limit of $R_{a}=3.2 \mu \mathrm{m}$. Roughness measured on side-milled surfaces was always double or triple the face-milled values, approaching $\mathrm{R}_{\mathrm{a}}=2 \mu \mathrm{m}$ for high $\mathrm{V}_{\mathrm{c}}, \mathrm{f}_{\mathrm{z}}$ and low $\mathrm{a}_{\mathrm{p}}$ (Figure $8 \mathrm{c}, \mathrm{d}$ ). The spread of results in the latter was also higher. In addition, the effects of feed-per-tooth on roughness were statistically greater for side-milled surfaces.

\subsubsection{Residual stresses}

Residual stresses are normally generated when machining a component and, when strongly tensile, can negatively influence the resistance to stress corrosion cracking [11]. Tensile residual stresses were observed in the dry-machined AISI 316L. The measured values were above the yield stress of the bulk material and were indicative of a large strain misfit between the deformed surface layer and the bulk microstructure.

Surface residual stresses appeared to increase with increasing $a_{p}$ and $V_{c}$ in Figure 9 , at low $f_{z}(0.15$ $\mathrm{mm})$. However, the feed-per-tooth values did not strongly influence measured residual stresses within the entire range of cutting parameters evaluated. In Figure 9, the dependence of residual stresses on cutting speed may be explained by the effects of temperature [14]; at higher speeds the additional friction increases the thermal field which, in turn, favours adhesion of the chip to the rake face of the tool. Figure 8 presents the effects of this process: at higher $V_{c}$ the surface roughness increased, a sign that the increased adhesion of the chip to the rake face of the tool impaired chip removal. Finally, metallurgical alterations and material volume changes are also dependent on temperature, ultimately leading to an increased tensile stress field when $\mathrm{V}_{\mathrm{c}}$ is raised [15]. In this case, the absence of lubricant helps in a better understanding of the underlying process, without masking the variation of friction between chip and rake face of the tool. It is prudent to expect that the addition of lubricant could partially mitigate the negative effects of increased $f_{z}$ and $V_{c}$ on surface residual stresses by providing extra cooling and lubrication to the tool-chip interface [12]. 

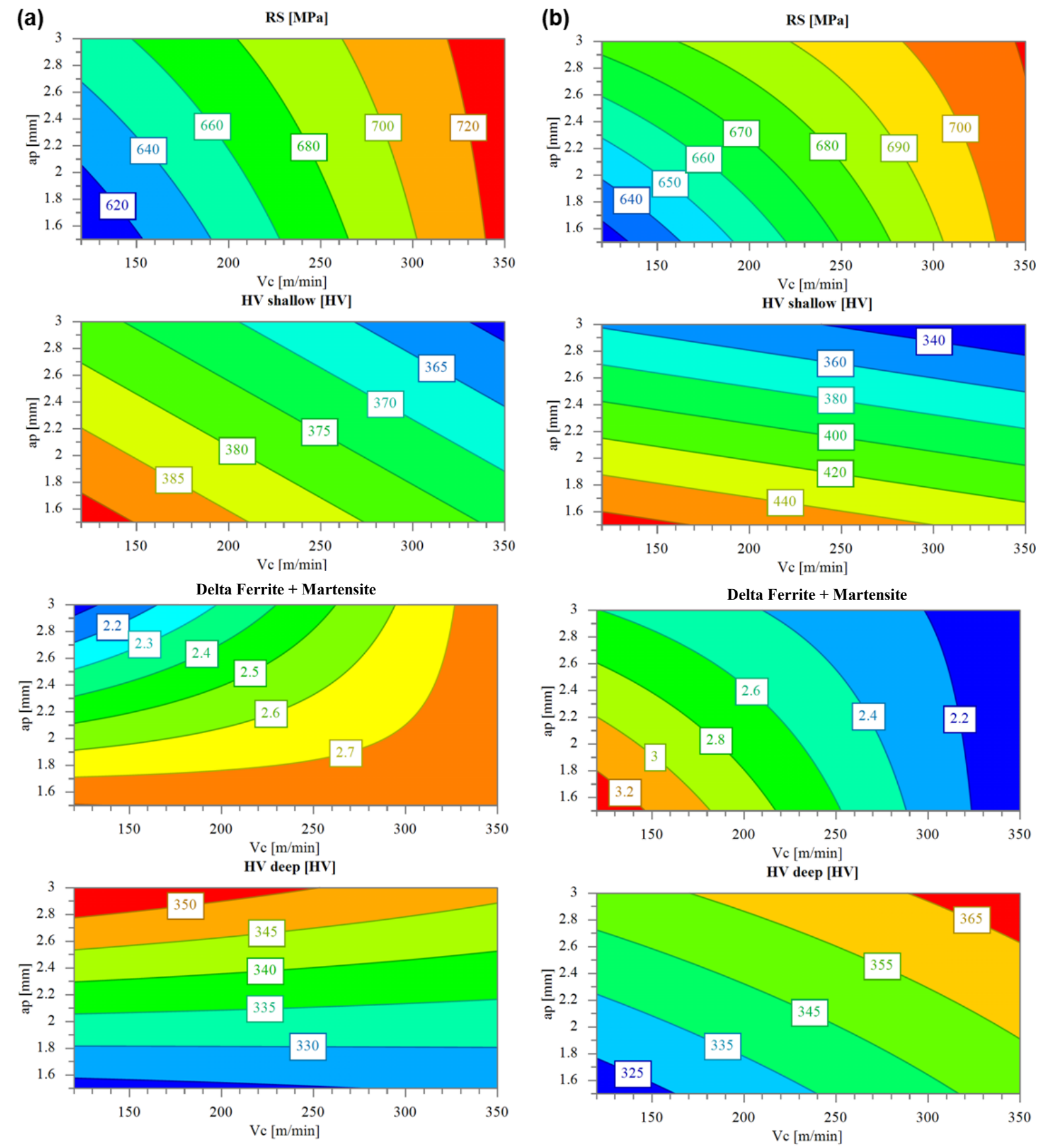

Figure 9: Contour plots of residual stresses, ferrite (delta + martensite) content and hardness for variable $V_{c}$ and $a_{p}$ at; a) $f_{z}=0.15 \mathrm{~mm}$, and b) $f_{z}=0.35 \mathrm{~mm}$.

\subsubsection{Surface hardening}

The hardness of the surface layer was measured with an indenter penetrating to a shallow depth $(\sim 5$ $\mu \mathrm{m}$ ) for each machined specimen. Low or no sensitivity of hardness to cutting speed was observed at high $f_{z}$, whereas at low $f_{z}$ a rather high response to $a_{p}$ was noted. Deep hardness $(\sim 25 \mu \mathrm{m})$ results were similar for both the $f_{z}$ cases $(0.15-0.35 \mathrm{~mm})$; a strong sensitivity of hardness to $a_{p}$ and marginal effects of $\mathrm{V}_{\mathrm{c}}$ on hardness was observed. In general deep-seated hardness measurements were less 
sensitive to changes in the machining parameters than the near-surface measurements and exhibited smaller differences between extremes in machining parameters.

The significantly higher-than-yield surface stresses observed in the dry machining of AISI 316L were indicative of substantial microstructural modifications in the near-surface regions. Previous studies on this class of material showed that surface layers mainly consisted of equiaxed austenite grains as well as strain-induced martensite [16]. Shallow (near-surface) hardness measurements showed sensitivity only for $a_{p}$ (Figure 9). This could be explained by progressive hardening due to increased deformation and steeper temperature gradients generated by the primary deformation zone. An opposite effect was shown in the case of deeper hardening yet with peak stress values significantly lower than the previous case. This was possibly a result of a larger (deeper) primary deformation zone [17].

A qualitative assessment of martensite content was attempted using a magnetic detector as conventional XRD is not suitable for measuring the thin surface layers $(<5 \mu \mathrm{m})$ in the present samples [18]. Figure 9 shows the significant effect of $f_{z}$ on martensite content whereas the effect of $a_{p}$ is more limited. This could be explained by the slower progression of the tool leading to increased abrasion on the freshly machined surface. At high $\mathrm{f}_{\mathrm{z}}$, the cutting tool moves forward faster and there is limited overlap of tool trajectories over the surface, therefore reducing the temperature and localised strain effects [19]. The measured martensite content should, however, be considered as qualitative only for a series of reasons. The probe depth with this magnetic technique is approximately $2 \mathrm{~mm}$, with gradually reducing sensitivity with depth. The measured percentage of martensite/delta ferrite represents, in fact, the weighted average over the measured volume and thus will deviate from representative values when the depth of the deformed surface layer varies. In Figure 9 the inverse proportionality between measured martensite content and depth of cut $a_{p}$ is noticeable. This trend is consistent with the observed increase in hardness for shallow penetration of the indenter and both indicate strong grain refinement and possibly a partial phase change from austenite to strain-induced martensite in the layer adjacent to the surface [16].

\subsection{Risk of failure in meeting acceptance parameters}

In manufacturing large components, it is of great importance to ensure that the finished product does not exceed the acceptance parameters. By estimating the statistical variability of the three main process parameters, namely cutting speed $V c$, depth of cut $a_{p}$, feed-per-tooth $f_{z}$, and employing the statistical model developed from the design of experiments, it is possible to calculate the probability that the finished component would not satisfy at least one of the critical parameters, namely surface 
roughness, residual stresses, hardness [10], which can be arbitrarily set for any given application.



Figure 10: Risk of failure in meeting at least one of critical parameters for different cutting parameters.

Given the maximum acceptable roughness commonly employed in the nuclear industry $\left(\mathrm{R}_{\mathrm{a}}=3.2 \mathrm{um}\right)$ and aiming to minimise residual stresses and hardness, it is possible to calculate the domain of cutting parameters that would have the lowest risk of the finished component failing to meet the set acceptance parameters. In Figure 10 the risk of failure to meet at least one of the critical parameters is represented in a sample colour map. Probabilities were calculated for a simulated sampling of one million components and are represented for $\mathrm{p}=0.95$. A normal distribution is assumed for the input cutting parameters. It is noticeable that both high and low $\mathrm{f}_{\mathrm{z}}$ bring a higher risk of failure whereas the lowest failure rate arises from medium $f_{z}$, medium-low $V_{c}$ and medium-high $a_{p}$. Within the limits of this approach, this range of parameters corresponds to a reduction of residual stresses, hardness and roughness of the component, the latter being the most limiting factor. The derived "risk of failure" map and the failure rate prediction represent a valuable tool for reduction of variability and the costs associated with machining and can be tailored for any given process and its acceptance parameters. 


\section{Conclusions}

The developed statistical model is useful for evaluating a robust set of machining parameters that would decrease the likelihood of a detrimental effect in the performance of dry milled AISI 316L components. Excellent agreement between experimental and statistical results was obtained for cutting parameters sampled within the experimental space used in this work, with reduced accuracy for cutting parameters increasingly further from the evaluated space.

Strain-induced martensite is a common occurrence in abusively machined austenitic stainless steels [24]. The deformed surface layer caused high tensile stresses and high local hardness. Its thickness appeared to be dependent on $\mathrm{a}_{\mathrm{p}}$ and $\mathrm{f}_{\mathrm{z}}$.

The statistical model also verified the interdependence of the milling parameters. In short, surface roughness values were excellent for face-milled specimens and acceptable for side-milled ones with a strong dependency on $\mathrm{f}_{\mathrm{z}}$ in both cases, whereas residual stresses increased with increasing $\mathrm{V}_{\mathrm{c}}$ and $a_{p}$, but decreased for higher values of feed-per-tooth $f_{z}$.

The generation of a sample "risk of failure" map allowed to demonstrate the capability of the DoE approach for preliminary selection of a range of cutting parameters that could optimise the material properties. The generation of similar maps for different processes and acceptance parameters would allow for an improvement in process control and its potential automation.

\section{Acknowledgments}

UK's Engineering and Physical Sciences Research Council (EPSRC) funding under the NNUMAN (New NUclear MANufacturing) research programme (EP/J021172/1) is acknowledged. The authors would like to thank Sandvik Coromant for access to their equipment, and assistance from their staff. 


\section{References}

[1] M.C. Bloom, CN. Newport, W.A. Fraser, Steel corrosion mechanism, The Growth and Breakdown of Protective Films in High-Temperature Aqueous Systems: $15 \% \mathrm{NaOH}$ at $316^{\circ} \mathrm{C}$. Journal of the Electrochemical Society, 111 (1964) 1343-1347.

[2] M.P. Groover, Fundamentals of Modern Manufacturing-Materials Processes and Systems, Prentice-Hall, Englewood Cliffs, NJ, USA, 1990.

[3] K. Tetal, Machining of Stainless Steels, in: ASM Handbook: Machining, Vol. 16 (Ed. by J.R. Davis), ASM International, USA, 1989, pp. 681-707.

[4] D.Y. Jang, T.R. Watkins, K.J. Kozaczek, C.R. Hubbard, O.B. Cavin, Surface residual stresses in machined austenitic stainless steel. Wear, 194 (1996) 168-173.

[5] F. Klocke, E. Brinksmeier, K. Weinert, Capability profile of hard cutting and grinding processes. CIRP Annals - Manufacturing Technology, 54 (2005) 22-45.

[6] H.K. Tönshoff, C. Arendt, R.B. Amor, Cutting of hardened steel. CIRP Annals - Manufacturing Technology, 49 (2000) 547-566.

[7] B.N. Pathak, K.L. Sahoo, M. Mishra, Effect of machining parameters on cutting forces and surface roughness in Al-(1-2) Fe-1V-1Si alloys. Materials and Manufacturing Processes, 28 (2013) 463-469.

[8] H. Gökkaya, The Effects of Machining Parameters on Cutting Forces, Surface Roughness, Built-Up Edge (BUE) and Built-Up Layer (BUL) During Machining AA2014 (T4) Alloy. Strojniški vestnik - Journal of Mechanical Engineering, 56 (2010) 584-593.

[9] L. Eriksson, S. Wold, Design of Experiments: Principles and Applications, Umetrics Academy, Umeå, Sweden, 2008.

[10] S. Ghosh, V. Kain, Microstructural changes in AISI 304L stainless steel due to surface machining: Effect on its susceptibility to chloride stress corrosion cracking. Journal of Nuclear Materials, 403 (2010) 62-67.

[11] W. Li, Y. Guo, C. Guo, Superior surface integrity by sustainable dry hard milling and impact on fatigue. CIRP Annals - Manufacturing Technology, 62 (2013) 567-570.

[12] F. Jiang, J. Li, L. Yan, J. Sun, S. Zhang, Optimizing end-milling parameters for surface roughness under different cooling/lubrication conditions. Int J Adv Manuf Technol, 51 (2010) 841-851.

[13] S.R. Das, K. Amaresh, D. Dhupal, Effect of machining parameters on surface roughness in machining of hardened aisi 4340 steel using coated carbide inserts. International Journal of Innovation and Applied Studies, 2 (2013) 445-453.

[14] N. Ben Moussa, H. Sidhom, C. Braham, Numerical and experimental analysis of residual stress and plastic strain distributions in machined stainless steel. International Journal of Mechanical Sciences, 64 (2012) 82-93. 
[15] C. Wiesner, Residual stresses after orthogonal machining of AlS1 304: numerical calculation of the thermal component and comparison with experimental results. Metallurgical Transactions A, 23 (1992) 989-996.

[16] R. M’Saoubi, J.C. Outeiro, B. Changeux, J.L. Lebrun, A. Morão Dias, Residual stress analysis in orthogonal machining of standard and resulfurized AISI 316L steels. Journal of Materials Processing Technology, 96 (1999) 225-233.

[17] J. Sun, Y.B. Guo, A comprehensive experimental study on surface integrity by end milling Ti6Al-4V. Journal of Materials Processing Technology, 209 (2009) 4036-4042.

[18] M.C. Shaw, Metal Cutting Principles, Oxford University Press, Oxford, UK, 1997.

[19] V. Marinov, Manufacturing Processes for Metal Products, Kendall Hunt Publishing Company, 2010.

[20] A.J. Wilkinson, Quantitative deformation studies using electron back scatter patterns. Acta Metallurgica et Materialia, 39 (1991) 3047-3055.

[21] A.J. Wilkinson, P.B. Hirsch, Electron diffraction based techniques in scanning electron microscopy of bulk materials. Micron, 28 (1997) 279-308.

[22] L. Sun, M.J. Thomas, B.P. Wynne, E.J. Palmiere, K.P. Mingard, B. Roebuck, Mapping microstructure inhomogeneity using electron backscatter diffraction in 316L stainless steel subjected to hot plane strain compression tests. Materials Science Technology, 26 (2010) 1477 1486.

[23] J.-Y. Kang, B. Bacroix, H. Réglé, K.H. Oh, H.-C. Lee, Effect of deformation mode and grain orientation on misorientation development in a body-centered cubic steel. Acta Materialia, 55 (2007) 4935-4946.

[24] R. M’Saoubi, J.C. Outeiro, H. Chandrasekaran, O.W. Dilon Jr., I.S. Jawahir, A review of surface integrity in machining and its impact on functional performance and life of machined products. International Journal of Sustainable Machining, 1 (2008) 203-236. 